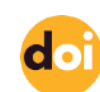

http://doi.org/10.22282/ojrs.2020.75

\title{
A COMPARISON OF BODY COMPOSITION, SPEED, FLEXIBILITY, AND \\ BALANCE IN FENCERS
}

\author{
Sercin KOSOVA, Merve KOCA KOSOVA, \\ Egemen MANCI, Firat ÖZDALYAN, \\ Hikmet GÜMÜŞ, \\ Celal GENÇOĞLU
}

ABSTRACT

\begin{abstract}
Fencing is a quite popular combatitive sport and applied in 3 different branches. In order to be successful in fencing, it is important to have advanced technical and tactical skills as well as many physical performance parameters. The aim of this study was determine and compare the body composition, speed, balance and flexibility of foil and sabre fencers. 24 foil and 29 sabre fencers included in the study. After body composition measurements, $30 \mathrm{~m}$ speed test, sit and reach test, and Y balance test were applied to all participants. There were no statistically differences between body compositions, $30 \mathrm{~m}$ speed test and
\end{abstract}

balance test scores of the two groups. Howewer, sit and reach test scores were better in foil fencers compared to sabre fencers $(p<.001)$. Foil plays at a lower tempo than sabre therefore fencers generally have longer lunge in foil. The specific trainings of foil especially for lunge may caused better flexibility levels for the foil fencers. Consequently, these parameters need to be developed in order to increase the competition performance in both branches of fencing.

Key Words: Body composition, speed, balance, flexibility, fencing 


\section{INTRODUCTION}

Fencing is one of the few sports in the Olympics since the first modern Olympic Games. All scoring is done electronically with the judge in this competitive sport. The bout occurs an area of $14 \mathrm{~m}$ long and between 1.5-2.0 m wide called 'piste'. Fencing is applied in 3 different branches as epée, foil, and sabre. Even though these 3 branches are very similar in basis, they contain different rules and regulations. The whole body is included as a target area in epée. While the length of the weapon is $110 \mathrm{~cm}$, its weight is $770 \mathrm{~g}$. In foil, the target area is limited only trunk. The length of the weapon is $110 \mathrm{~cm}$ like epée and its weight is $550 \mathrm{~g}$. There are invalid touch regions in foil differently from other branches. In sabre, upper body is the target area so head and arms are also included. The length of the weapon is $105 \mathrm{~cm}$ and its weight is $550 \mathrm{~g}$ in sabre. At least $500 \mathrm{~g}$ of pressure must occur in order to valid touch for foil yet the necessary minimum pressure is $750 \mathrm{~g}$ for epée. However, it is sufficient to touch the fencers' upper body for sabre.

Each individual bout starts with a group competition which 6 or 7 athletes participate called 'poul'. These group bouts are played over 5 points while the duration is a maximum 3 minutes. According to the results of group competitions, bouts of direct elimination are played. Direct elimination bouts are result in 15 points and include 3 periods. Total time of the periods is 9 minutes further the break between periods is 1 minute. Whoever scores 15 points first or who has the highest number of points after 3 periods, wins the bout.

Anaerobic metabolism is predominantly used in fencing. The competition profile includes low-intensity movements with different rest periods as well as e series of explosive attacks, lunges and change of direction (Guilhem, Giroux, Couturier, Chollet and Rabita, 2014; Wylde, Tan and O'Donoghue, 2013). This open-skilled branch consists of sudden acceleration and deceleration, direction changes of the extremities with rapid movements, as well as the whole body direction changes (Redondo, Alonso, Sedano and de Benito, 2014; Sheppard and Young, 2006). The defensive and offensive movements in a fencing bout are based on a quite a lot of change of direction movements (Roi and Bianchedi, 2008) in this way the change of direction constitute the basic structure of movements in the bout. During change of direction movements it is crucial that fencers maintain their balance and be able to continue their actions in expected quickness. In addition, physical performance parameters of fencers like flexibilitiy 
and speed are important variables for take points in bouts. Determination of these parameters will give opinion about physical profiles and performance of fencers. Therefore, this study aims to investigate the body composition, speed, balance and flexibility of a mixed group of fencers from different clubs in Turkey and also compare the results of foil fencers and sabre fencers.

\section{METHOD}

The total number of fencers included in the study was 53 and there were 24 (11 female 13 male) foil fencer and 29 (15 female - 14 male) sabre fencer. They were competing in the U14-17 age categories and participating in the "Fencing Fest International Fencing Camp" held in Çanakkale.

The participants' height $(\mathrm{cm})$ was measured using a tape measure without shoes (barefoot). Body masses ( $\mathrm{kg}$ ) and body compositions of all fencers were determined before the breakfast by body composition analyser (Inbody 270). The $30 \mathrm{~m}$ speed test, sit and reach test, and Y balance test (Y-BT) were applied to the participants.

30 m speed test: New Test power timer 3000 series photocell was used for the test. The participants were asked to complete the $30 \mathrm{~m}$ track as quickly as possible and repeated the test twice. Best results of the two trials were recorded in $\mathrm{m} / \mathrm{sec}$.

Sit and reach test: Sit and reach test is a common test used to measure hamstring and lower back flexibility (Ayala, de Baranda, Croix and Santonja, 2012).The participants kept their legs extended and touched the board with their heels without shoes while sitting on the apparatus. They were asked to reach as far as possible to board and wait at this situation. The test were performed twice and best results were evaluated.

$Y$ balance tests: Y-BT was used to measure the ability to maintain balance (Linek, Sikora, Wolny and Saulicz, 2017). All Y-BT attempts were performed in the same order which respectively anterior direction, posterolateral direction and finally posteromedial direction. The participants were asked to reach the furthest point with their toe tip while standing on one leg (barefoot) in a center of the setup with hands placed on the wing of ilium. The measurement procedure consisted of nine attempts. Six initial attempts were performed to familiarize the 
fencers with the testing procedure while the last three attempts' results were used for statistical analysis. All fencers' lower limb length (the distance from the anterior superior iliac spine to the medial malleolus) were measured for normalize the Y-BT results. The measurement was carried out with a tape measure while athletes waiting on a standing position. The following formula was used for evaluating the single results: (the distance obtained in an attempt/relative length of the limb) x 100. Additionally, another formula was used to calculate composite reach distance for total score of each leg: $[($ anterior + posterolateral + posteromedial $) /($ limb length x3)] x 100 (Plisky, Rauh, Kaminski and Underwood, 2006).

The research protocol was approved by the Local Ethics Board for Non-Interventional Studies (Decision number: 2019/11-32) and informed consent was obtained from the adults and legal representatives of participants under the age of 18 that they were volunteers.

Data analyses: Basic descriptive analyses were performed where the results were expressed by the mean and standard or standard deviation for the quantitative variables. The normality of the variables was studied using the Shapiro-Wilk test. Levene's test was used to assess the homogeneity of variances. Anthropometrical measurments, sit and reach test, $30 \mathrm{~m}$ speed test and Y-BT differences were assessed with the independent t-test. The results are presented as mean values and standard deviations.

The value of $p$ was adjusted to $p<0.05$. All analyzes were performed using the IBM SPSS Statistics 20. 


\section{RESULTS}

After dividing into groups of foil and sabre, gender differences were assessed and a homogeneous distribution was observed according to the Levene's Test result. Accordingly, the groups were evaluated without distinction between boys and girls. Descriptive data on the body composition of the fencers were presented as means and standard deviations in Table 1. There was no statistical difference between the descriptive analyses of body composition of the two groups ( $\mathrm{p}>.05)$.

Table 1. Descriptive Analyses of Body Composition According To Groups

\begin{tabular}{lccccc} 
& $\begin{array}{c}\text { FOIL FENCERS } \\
\text { Mean }(\mathrm{ms}) \pm \mathrm{SD} \\
(\mathrm{n}=24)\end{array}$ & $\begin{array}{c}\text { SABRE FENCERS } \\
\text { Mean }(\mathrm{ms}) \pm \mathrm{SD} \\
(\mathrm{n}=29)\end{array}$ & $\mathrm{t}$ & $\mathrm{df}$ & $\mathrm{p}$ \\
\hline Age $(\mathrm{year})$ & $14.15 \pm 1.20$ & $14.63 \pm 1.05$ & -1.531 & 51 & .132 \\
Height $(\mathrm{cm})$ & $163.04 \pm 10.46$ & $167.02 \pm 9.37$ & -1.459 & 51 & .151 \\
Weight $(\mathrm{kg})$ & $55.23 \pm 10.41$ & $57.24 \pm 12.61$ & -.624 & 51 & .536 \\
Muscle mass $(\mathrm{kg})$ & $22.88 \pm 5.38$ & $24.99 \pm 5.80$ & -1.362 & 51 & .179 \\
Fat mass $(\mathrm{kg})$ & $13.03 \pm 6.43$ & $11.73 \pm 5.94$ & .765 & 51 & .448 \\
Fat percentage $(\%)$ & $22.710 \pm 9.57$ & $20.18 \pm 7.09$ & 1.070 & 41.587 & .291 \\
Body mass index $\left(\mathrm{kg} / \mathrm{m}^{2}\right)$ & $20.57 \pm 2.81$ & $20.36 \pm 3.10$ & .254 & 50.546 & .801 \\
\hline
\end{tabular}

Sit and reach test, and $30 \mathrm{~m}$ speed test $(\mathrm{m} / \mathrm{s})$ of the fencers were presented as means and standard deviations in Table 2. The results showed that sit and reach test scores were lower in sabre fencers $(7.31 \pm 6.79 \mathrm{~cm})$ compared to foil fencers $(15.96 \pm 6.29 \mathrm{~cm})$, a mean difference of $8.65(95 \% \mathrm{CI}, 5.01$ to 12.28$) \mathrm{cm}, \mathrm{t}(51)=4.772, \mathrm{p}=.001$. There was no statistical difference between $30 \mathrm{~m}$ speed test of the two groups (p>.05).

Table 2. Sit and Reach Test and $30 \mathrm{~m}$ Speed $(\mathrm{m} / \mathrm{s})$ Test of Fencers

\begin{tabular}{|c|c|c|c|c|c|}
\hline & $\begin{array}{l}\text { FOIL FENCERS } \\
\text { Mean }(\mathrm{ms}) \pm \mathrm{SD}\end{array}$ & $\begin{array}{c}\text { SABRE FENCERS } \\
\text { Mean }(\mathrm{ms}) \pm \mathrm{SD}\end{array}$ & $\mathrm{t}$ & $\mathrm{df}$ & $\mathrm{p}$ \\
\hline $\begin{array}{c}\text { Sit and reach } \\
\text { Foil fencers }(n=24) \\
\text { Sabre fencers }(n=29)\end{array}$ & $15.96 \pm 6.29$ & $7.31 \pm 6.79$ & 4.772 & 51 & .001 \\
\hline $\begin{array}{l}30 \mathrm{~m} \text { Speed Test }(\mathrm{m} / \mathrm{s}) \\
\text { Foil fencers }(\mathrm{n}=24) \\
\text { Sabre fencers }(\mathrm{n}=28)\end{array}$ & $5.93 \pm 0.58$ & $6.04 \pm 0.51$ & -.730 & 50 & .469 \\
\hline
\end{tabular}


Y-BT scores of the fencers were presented as means and standard deviations in Table 3. There was no statistical difference between all balance scores of the two groups ( $p>.05)$.

Table 3. Comparison of Y Balance Test of Fencers

\begin{tabular}{lccccc}
\multicolumn{1}{c}{ Y Balance Test } & $\begin{array}{c}\text { FOIL FENCERS } \\
\text { Mean }(\mathrm{ms}) \pm \mathrm{SD} \\
(\mathrm{n}=24)\end{array}$ & $\begin{array}{c}\text { SABRE FENCERS } \\
\text { Mean }(\mathrm{ms}) \pm \mathrm{SD} \\
(\mathrm{n}=23)\end{array}$ & $\mathrm{t}$ & $\mathrm{df}$ & $\mathrm{p}$ \\
\hline Anterior - R & $75,70 \pm 6.18$ & $78.79 \pm 7.25$ & -1.577 & 45 & .122 \\
Posterolateral - R & $103.02 \pm 8.50$ & $105.30 \pm 7.94$ & -.951 & 45 & .347 \\
Posteromedial - R & $100.43 \pm 10.50$ & $101.53 \pm 10.21$ & -.363 & 45 & .718 \\
Anterior - L & $76.92 \pm 6.33$ & $78.87 \pm 6.68$ & -1.027 & 45 & .310 \\
Posterolateral - L & $104.58 \pm 7.98$ & $105.48 \pm 7.63$ & -.396 & 45 & .694 \\
Posteromedial -L & $98.50 \pm 10.12$ & $99.61 \pm 9.13$ & -.395 & 45 & .695 \\
Right Total Score & $107.29 \pm 12.53$ & $109.81 \pm 19.00$ & -.538 & 45 & .593 \\
Left Total Score & $107.60 \pm 11.95$ & $105.92 \pm 9.38$ & .533 & 45 & .597 \\
\hline
\end{tabular}

\section{DISCUSSION}

Body composition, flexibility, speed and balance of the fencers were evaluated in this study. There were no differences between body compositions of foil and sabre fencers at the same time their body mass indexes were within normal limits. There were no differences in 30 $\mathrm{m}$ speed test and Y-BT results between the groups of foil and sabre. However the foil fencers were found more flexible than sabre fencers according to sit and reach test results.

Norjali et. al investigate the physical performance of young fencers and they found similar results in $30 \mathrm{~m}$ speed test with the present study (Norjali, Mostaert, Pion and Lenoir, 2018). Most of the offensive actions designed to get touch in fencing are concluded with lunge. The speed of the lunge is critical to success of these attacks. At the same time speedy defensive actions are necessary to respond toe the rival's offensive action. Being able to recover rapidly from the lunge takes advantage to fencer for the next action. An international competition that 64 fencers competed in direct elimination bout was analyzed by Roi and Bianchedi (2008) and they found the number of lunges for one bout between 66 and 210. Dynamic movements such as steps or jumps for attack preparation and lunges for get touch, highly depends on muscle strength, power (Poulis, Chatzis, Christopoulou and Tsolakis, 2009; Tsolakis and Tsiganos, 2008) and neuromuscular function of the lower limb (Poulis, Chatzis, Christopoulou and Tsolakis, 2009). At the same time, being able to apply all these skills in accordance with the course of the bout requires an advanced speed skill. Generally, sabre is played at a faster tempo than foil. Although there are differences in the cadence of the bout between these two 
branches, the findings of the present study showed no difference between the $30 \mathrm{~m}$ speed test of foil and sabre fencers. A plausible explanation for this finding may be that fencers were too young for inter-disciplinary speed differences to occur.

In a study conducted on fencers, it was observed that there was a positive relationship between leg strength and balance (Gülaç, 2019). Balance is another important factor in achieving high performance in fencing branches (Cook, 2003). Fencing also improves balance by en garde positions and steps forward and backward because the repetition of motor skills enables the development of postural sensorimotor skills. Advanced visual tracking and quick motor skills are required while maintaining balance control to be successful during the bout (Herpin and diğerleri, 2010). The present findings suggest that there were no differences in Y-BT results between the two groups. The same guard position is used in all three branches of fencing besides lunges and returning to guard position from the lunges are similar. This means that balance development is expected to be parallel in all branches. So the results of the Y-BT seem to be compatible with the nature of fencing branches.

The length of the lunge can be related to the flexibility of the fencer. In a study of medallist and non-medallist young fencers flexibilities were measured, the results of sit and reach tests were $20.38 \pm 7.55 \mathrm{~cm}$ for medallist and $24.19 \pm 12.69$ for non-medallist (Norjali, Mostaert, Pion and Lenoir, 2018). In another study Tsolakis, Kostaki and Vagenas (2010) measured the sit and reach test of fencers and they reported the results as $12.6 \pm 7.44 \mathrm{~cm}$. The sit and reach test results of this study were $15.96 \pm 6.29 \mathrm{~cm}$ for foil fencers and $7.31 \pm 6.79 \mathrm{~cm}$ for sabre fencers. The differences in the literature may be due to different measurement methods as well as the age, gender, training experience and branch of the fencers. To explain statistically difference in sit and reach tests of two groups in current study, it may be necessary to state the tempo differences between the foil and sabre. Since foil plays at a lower tempo, foil fencers have longer lunges than sabre fencers. Generally, fencers take the steps at a slower pace when trying to approach to rival in foil so they keep their distance from the rival farther than the sabre and apply the lunge as this distance allows. On the sabre, the remaining distance for the lunge is shorter due to faster and more dynamic approach steps. So, it can be said that flexibility is prominant for foil due to the necessary longer lunges furthermore because of specific trainings of foil, foil fencers could have better flexibility levels. 
As a result, parameters such as speed, balance, and flexibility are determining performance in fencing.Trainers and fencers should include these parameters in their training programs to increase competition performance. Although we associate long lunges and flexibility in foil fencers, it is important for all fencing branches to develop flexibility and to include specific flexibility exercises in training programs.

\section{REFERENCES}

Ayala, F., de Baranda, P. S., Croix, M. D. S., \& Santonja, F. (2012). Reproducibility and criterion-related validity of the sit and reach test and toe touch test for estimating hamstring flexibility in recreationally active young adults. Physical Therapy in Sport, 13(4), 219-226.

Cook, G. (2003). Athletic body in balance: Human kinetics.

Guilhem, G., Giroux, C., Couturier, A., Chollet, D., \& Rabita, G. (2014). Mechanical and muscular coordination patterns during a high-level fencing assault. Medicine \& Science in Sports \& Exercise, 46(2), 341-350.

Gülaç, M. (2019). Examination of the Correlation between Dynamic Balance and Leg Strength of 11 and 12-Year-Old Children Who Have Fencing Training. Asian Journal of Education and Training, 5(1), 39-43.

Herpin, G., Gauchard, G. C., Lion, A., Collet, P., Keller, D., \& Perrin, P. P. (2010). Sensorimotor specificities in balance control of expert fencers and pistol shooters. Journal of Electromyography and Kinesiology, 20(1), 162-169.

Linek, P., Sikora, D., Wolny, T., \& Saulicz, E. (2017). Reliability and number of trials of Y Balance Test in adolescent athletes. Musculoskeletal science and practice, 31, 72-75.

Norjali, R., Mostaert, M., Pion, J., \& Lenoir, M. (2018). Anthropometry, physical performance, and motor coordination of medallist and non-medallist young fencers. ARCHIVES OF BUDO, 14, 33-40.

Plisky, P. J., Rauh, M. J., Kaminski, T. W., \& Underwood, F. B. (2006). Star Excursion Balance Test as a predictor of lower extremity injury in high school basketball players. Journal of orthopaedic \& sports physical therapy, 36(12), 911-919.

Poulis, I., Chatzis, S., Christopoulou, K., \& Tsolakis, C. (2009). Isokinetic strength during knee flexion and extension in elite fencers. Perceptual and motor skills, 108(3), 949-961.

Redondo, J. C., Alonso, C. J., Sedano, S., \& de Benito, A. M. (2014). Effects of a 12-week strength training program on experimented fencers' movement time. The Journal of Strength \& Conditioning Research, 28(12), 3375-3384.

Roi, G. S., \& Bianchedi, D. (2008). The science of fencing. Sports Medicine, 38(6), 465-481. 
Sheppard, J. M., \& Young, W. B. (2006). Agility literature review: Classifications, training and testing. Journal of sports sciences, 24(9), 919-932.

Tsolakis, C., Kostaki, E., \& Vagenas, G. (2010). Anthropometric, flexibility, strength-power, and sport-specific correlates in elite fencing. Perceptual and motor skills, 110(3_suppl), 1015-1028.

Tsolakis, C., \& Tsiganos, G. (2008). The influence of training on neuromuscular factors in elite and non elite fencers. Serbian Journal of Sports Sciences, 2(1-4), 59-65.

Wylde, J. M., Tan, F. H., \& O’Donoghue, G. P. (2013). A time-motion analysis of elite women's foil fencing. International Journal of Performance Analysis in Sport, 13(2), 365-376. 